Fecha de recepción: diciembre 2017

Fecha de aceptación: marzo 2018

Versión final: julio 2019

\section{La Nobleza de Estado, algunas reflexiones a partir del trabajo de campo con elites educativas en la Argentina}

Victoria Gessaghi ${ }^{\star}$ y Alicia Méndez ${ }^{\star *}$

Resumen: El trabajo analiza las condiciones de lectura del libro La nobleza de estado en el marco de dos investigaciones que abordan la educación de dos grupos de privilegio en la sociedad argentina. Nos interesa colocar distintos acentos al texto en cuestión, en virtud de cómo algunos problemas de La nobleza resuenan en el trabajo de campo llevado adelante en dichas investigaciones. El artículo explora en primer lugar la recepción que tuvo esta obra seminal de Bourdieu en nuestro campo y destaca sus aportes principales para el estudio de las elites en Argentina. Seguidamente, se describen los modos en que se despliega en nuestros respectivos campos el "efecto de dignidad" otorgado por un título tal como lo conceptualiza Bourdieu en su trabajo. Por último, se documentan las diversas formas en que, en los casos estudiados, el capital se construye, se combina, se reproduce; y el lugar que ocupan las escuelas de elite en esa construcción.

Palabras clave: Nobleza de Estado - Bourdieu - Clase alta - Colegio Nacional de Buenos Aires - Meritocracia.

[Resúmenes en inglés y portugués en las páginas 48-49]

${ }^{*}$ Dra. En Antropología Social. (UBA) Magister en Ciencias Sociales con orientación en Educación (FLACSO). Investigadora Adjunta del CONICET. Profesora de la Universidad de Buenos Aires. Autora de "La educación de la clase alta argentina. Entre la sangre y el mérito” Siglo XXI. E-mail: victoriagessaghi@hotmail.com

${ }^{(*)}$ Dra. En Ciencias Sociales (UBA). Magisten en Comunicación y Cultura (UBA). Docente en UBA/FSOC y FLACSO. Investigadora del Instituto de Desarrollo Económico y Social (IDES). Autora de El Colegio. La formación de una elite meritocrática en el Nacional Buenos Aires, Sudamericana. alicimzv@yahoo.com

\title{
Introducción
}

En este trabajo quisiéramos referirnos, en primer lugar, a las condiciones en que se da nuestra lectura del libro La nobleza de estado. En segundo lugar, nos interesa colocar distintos acentos al texto en cuestión, acentos puestos en virtud de cómo algunos problemas 
de La nobleza resuenan en la representación que nosotras tenemos de nuestro trabajo de campo. Hablamos de acentos porque las instituciones en estudio: las escuelas formadoras de la clase alta argentina y el Colegio Nacional de Buenos Aires (CNBA), por un lado, y el sistema de formación de elites francés en el que los cursos preparatorios a las grandes écoles (CPGE) poseen un lugar central, por el otro, no son comparables vis à vis. Sí podemos pensar este universo complejo a partir de categorías nativas. Las instituciones argentinas formadoras de elite corresponden a la educación secundaria y los CPGE franceses corresponden al nivel superior, aunque no universitario. En este sentido, consideramos que es también válido mirar comparativamente sistemas nacionales de formación de elites haciendo foco en la institución que para la vida posterior de sus egresados resulta decisiva: la socialización en estos colegios argentinos es central respecto de la trayectoria profesional, amistosa, y matrimonial de sus egresados. Para los sociólogos franceses, los cursos preparatorios en Francia son más gravitantes que los colegios secundarios del barrio latino, como el Luis Le Grand y el Henry IV. En términos de Bourdieu, los diplomas obtenidos en el sistema de educación superior tienden a funcionar como una garantía de dignidad "que dispensa en forma definitiva a su poseedor de la obligación de rendir pruebas, de demostrar en la práctica sus capacidades", esto es, como un título de nobleza (Bourdieu, 2013:172). Aquí comentaremos algunos de los modos en que se despliega en nuestros respectivos campos ese "efecto de dignidad" otorgado por un título.

Algunos de los problemas planteados en el libro que nos ocupa, que resuenan en nuestro trabajo de campo, tienen que ver con el modo en que el capital se construye, se combina, se reproduce; y, en definitiva, se constituye como tal, y a su vez con el lugar que ocupan las escuelas de elite, en esa construcción.

La Nobleza es un libro publicado en 1989 y traducido al castellano en 2013. El arco que va entre el momento de la escritura y el de la lectura que hoy hacemos es un tiempo densamente semiotizado por los textos de los que ese libro fue una condición de producción. Es decir, los textos que surgieron como respuesta celebratoria o crítica a La Nobleza condicionan nuestra recepción actual de ese escrito primero, porque nuestra mirada en tanto investigadoras y lectoras se formó con esas lecturas. También, lo que pudo y no pudo ser escrito en el campo cultural francés de los años ochenta hegemonizado por la Filosofía es otra condición de nuestra recepción del texto bourdieusiano: el trabajo etnográfico; las observaciones y las entrevistas realizadas en conjunto con Monique de Saint Martin e Yvette Delsaut sobre los alumnos de las clases preparatorias quedaron en gran medida ocultas, confinadas al journal de terrain, presas de los límites de lo que en ese entorno político académico se consideraba "ciencia". Eso que falta también produce sentidos en nuestra lectura. Muy Brevemente: no podemos dejar de leer hoy cualquier texto de Bourdieu, sin atender a cómo esa obra fue leída por Bernard Lahire y el modo en que este sociólogo de Lyon luchó contra Bourdieu al escribir "El hombre plural". Si nuestra mirada fuera sociológica, seguramente toda la sociología pragmática de Boltansky también hubiera configurado el espacio de recepción crítica de esta obra. Sin embargo, dada nuestra formación en el enfoque etnográfico, las discusiones de Lahire en torno de la homogeneidad del habitus y la pluralidad de la acción, nos permiten abrir los matices y recuperar las heterogeneidades que el caso argentino introduce en la teoría crítica, y que no se explican a partir de describir todo lo que la escuela o las elites vernáculas se distancian del análisis 
francés -casi como una definición por carencia- sino por la irreversible multiplicidad de mediaciones y apropiaciones desde los cuales los sujetos construyen sus prácticas.

\section{Nuestras investigaciones}

Una de nuestras investigaciones (Gessaghi, 2016) abordó los procesos de jerarquización en la Argentina a partir de documentar el trabajo de formación la clase alta ${ }^{1}$ Ésta se presenta constituida por una red de grupos de parentesco cuyos apellidos son asociados a la "elite fundadora de la patria" y a "la tierra" en tanto se desenvuelven principalmente en el sector agroganadero. El apellido, la antigüedad, el vínculo con la tierra y la historia nacional son recursos que estos grupos despliegan en las disputas por pertenecer a la clase alta (Gessaghi, 2016). Y a partir de allí, la autora se preguntó cómo participaba la educación en el trabajo de formación de este grupo social. Lo que recogió fue la importancia decisiva de ciertas escuelas en la construcción de relaciones de interconocimento y reconocimiento entre "las familias tradicionales". A lo largo de un extenso trabajo de campo, Gessaghi documentó la sostenida elección de determinadas instituciones por parte de las distintas generaciones de la clase alta. Estos colegios se caracterizan por ser de gestión privada, católicos y por impartir una educación diferenciada por género. Fundados entre 1915 y 1950, se han ido localizando en la zona norte de la provincia de Buenos Aires. Lejos de pretender una "educación de excelencia", los sujetos sostienen esta preferencia porque el colegio es el de "su medio social", el de "su clase" y que alli "todo el mundo se conoce". Una entrevistada justificaba la elección familiar de cierta institución porque: "no había otra posibilidad, mi mamá fue allí y les importaba la cosa social, no era en función del nivel intelectual, lo social era que era gente como ellos, enseñar mejor no importaba. Por ahí, unas primas mías habian ido, para ellos era un ambiente cómodo, que conocían".

Los alumnos están relacionados por lazos de parentesco ya que hermanos y primos, tíos y abuelos concurren o asistieron a la misma institución. Así, las familias se van aglutinando en una red que favorece las relaciones entre sus miembros y se va construyendo una atmósfera familiar, mediante el trabajo de crear, mantener y cuidar ese mundo social. Una maestra con treinta años de trayectoria en una de dichas instituciones comentaba que las familias del colegio

Se conocen mucho porque como las abuelas, madres, la hermana del padre venía y entonces la otra quiere mandar a su hija, entonces las familias se conocen mucho (...) de treinta que tenés en el grado, hay veinte que se súper conocen porque o veranean en Punta del Este o veranean en Cariló o tienen la casa en el mismo barrio o van al mismo club el fin de semana (...) son muy de ir, de venir, de almorzar en un lado y tomar el té en lo del otro (...) entonces esto se va dando como de familia en familia, son bastante como un clan conocido, no un clan cerrado sino conocido. (...) hay mucho ambiente familiar.

Los lazos entre familias y escuela son fomentados desde el propio colegio a través del reclutamiento del alumnado: tienen prioridad, no sólo los hermanos, sino también quienes 
tengan familiares que sean ex alumnos de la institución. El proceso de selección de los estudiantes dura un año. Los candidatos deben presentar una carpeta con un formulario con los datos de ambos padres, escuela en la que estudiaron, apellidos, trabajos actuales, una foto de la familia y los datos de los hijos. En una segunda instancia, los adultos son evaluados en una entrevista personal, luego los niños deben pasar una serie de exámenes de inglés, lengua y matemática y otro psicopedagógico. Algunas instituciones solicitan también el pago de una cuota de ingreso al iniciar la escuela primaria. Esa "membresía" cohesiona a las familias "que pertenecen". La distinción de las familias de la clase alta radica en su apellido y en su origen pero las instituciones en las que se educan sus miembros se vuelven relevantes en la construcción del reconocimiento social. En el colegio -además de pulir lo que sea necesario según procedencia- los sujetos edifican y son imbuidos del "ethos" de la institución y de sus miembros tal como expresa la revista de exalumnas de uno de dichos espacios: "esta amistad comenzó a forjarse el día que ingresamos a nuestro querido [colegio] y sin que nos diéramos cuenta fue creciendo a través de los años-inclusive durante aquellos en los que nos mantuvimos distanciadas por diferentes circunstancias. Las vueltas de la vida hicieron que de a poco nos fuéramos reencontrando y viendo que las antiguas diferencias se habian transformado en coincidencias; seguramente debido al School Spirit del [colegio] que nos cortó a todas con la misma tijera".

Edificar esa mística, que "borra las diferencias" entre sus alumnos y construye distancias con "los otros", es parte esencial de la tarea de la escuela. El colegio se presenta como el lugar en que se encuentran varias generaciones de un "clan". La institución continúa la historia de la familia al recibir a cada nueva generación. Este trabajo de ligar generaciones permite la inscripción en una larga duración y funda vínculos estables y atemporales. Contribuye a hacer de la antigüedad el principio oculto de las jerarquías de poder y a poner un obstáculo a la los recién llegados (Bourdieu, 2013).

Méndez estudió El Colegio Nacional de Buenos Aires (Méndez, 2013). Algunas de las conclusiones que aquí se presentan para la comparación surgen de una investigación doctoral que implicó ya sea, la realización de una prosopografía (la elaboración de una biografía colectiva de sujetos por alguna razón comparables), en este caso, de algunos grupos de egresados que resultan paradigmáticos en el proceso de formación de jóvenes en la Argentina; ya sea, la lectura rigurosa de autobiografías; ya sea, el análisis de legajos de alumnos que pasaron por el CNBA desde el año 1897 a 1999, separados en doce muestras (que suman en total 773 ingresantes) tomadas en forma sistemática y al azar en dos años no consecutivos cada veinte.

Esas fuentes, como aquellas a las que se accede a través de la prosopografía, han aportado datos valiosos para la investigación, pero como ha escrito el historiador italiano Giovanni Levy (1989) solo nos enseñan sobre los resultados finales de las decisiones de los actores: sobre los actos. Y, es más: sobre los actos estadísticamente más frecuentes, pero no sobre los procesos de elaboración de las decisiones.

A esa evidencia solo es posible acceder a partir de la etnografía. El trabajo etnográfico consistió en entrevistar, entre diciembre de 2004 y octubre de 2009, a algo más de cincuenta personas egresadas en distintos años del CNBA, así como visitar los lugares en los que algunos se hospedaban y estudiaban durante su estada en París para realizar estudios de posgrado, comer con ellos en dos comedores universitarios y presenciar modos 
de intercambio entre sí, con otros estudiantes argentinos, latinoamericanos y franceses. La investigación implicó también visitar repetidamente la Asociación de Ex Alumnos; en una oportunidad, asistir a una conferencia brindada por egresados de distintas edades que eran miembros de la masonería, y participar en el Aula Magna del CNBA de actos organizados por el Colegio a propósito del aniversario de egreso de alguna camada, de bienvenida a las nuevas promociones y de homenajes a determinadas figuras. Asimismo, para entrevistar exalumnos mientras hacían su trabajo, fue oportuno concurrir a despachos oficiales, a estudios de abogados del microcentro porteño, a la sala de profesores del CNBA (algunos de ellos son docentes de la institución), a presentaciones de libros y a defensas de tesis en las que participaba algún exalumno como tesista o evaluador. Para observar lo que una elaboración posterior llevaría a pensar en términos de "modos de autoafirmación en tanto colectivo social", fue enriquecedor visitar un stand en la feria del libro gestionado por la misma asociación, así como leer con atención los testimonios que algunos visitantes -egresados del CNBA- dejaron en el cuaderno de notas allí dispuesto. Asimismo, la asistencia a clases de francés; como otros espacios de la vida académica en mayor o menor medida ligados a la labor investigativa, pero en la que tomaban parte egresados del Colegio, permitió observar modos de adquirir conocimientos y de usar y valorar el propio tiempo. Para ver formas de sociabilidad entre los egresados, formas que pueden entenderse como parte de una lógica de trabajo en pos de la perduración de un colectivo social, fue importante la concurrencia a reuniones privadas, comidas y casamientos. Así, las diversas formas en que se desplegó esa "observación participante" permitieron relevar tanto criterios para elegir padrinos de boda como identificar cuáles eran los atributos y/o episodios que los actores seleccionaban para presentar a la propia persona ante un auditorio en un evento social en el que eran los homenajeados, los anfitriones o los novios consortes.

Esa larga investigación permitió ver que más que solo familias tradicionales, el Colegio exhibe como parte de su tradición sujetos que no necesariamente son "herederos" en términos de Bourdieu y que han trascendido por sus logros individuales, más allá de que sus padres o hijos puedan ser exalumnos y de familias también inscriptas "en una larga duración”. Como escribió Bourdieu a propósito de l'ENS, son alumnos capaces de citar de memoria el nombre de antiguos premiados (Bourdieu, 2013:27). Un rasgo que quizás distinga a las instituciones formadoras de elite con vocación meritocrática, que consiste en tomar la saga de notables que los precedieron, como un contenido más a incorporar durante la socialización escolar. Entre fines del siglo XIX y la década de 1930 reclutó a una población diversa, entre la que se contaron hijos de familias de antigua data e influyentes, pero mayormente de origen inmigratorio, perfil que en los años sucesivos iría acotando su heterogeneidad social pero no su diversidad cultural, política y de hecho residencial.

El del CNBA fue un espacio socializador eficaz en cuanto a su función de construir identidades sociales, establecer sentidos de pertenencia y proveer de recursos culturales significativos en los que tiene especial influencia la idea del esfuerzo. En la transmisión de esa moralidad se rubrica la pertenencia a una tradición, la ilustrada y laica, pero básicamente tolerante y abierta, desde donde moldean sus expectativas. Esas circunstancias marcan un límite respecto de una sociedad vivida como un "afuera".

Muchos egresados han manifestado que sienten que han tenido buenas oportunidades profesionales a lo largo de sus vidas gracias a haber realizado un gran esfuerzo durante 
su adolescencia, una prueba descomunal como la del ingreso parece haber modelado la forma en que comenzaron a percibir a quienes nunca pasaron por ese desafío tan agotador: a los amigos del barrio, con más tiempo que ellos para dedicar al esparcimiento, y a los padres. También el terror de dejar de pertenecer a esa institución a la que tanto les costó entrar, o de no poder adaptarse, son constricciones que suelen dar cabida a un modo nuevo de ver a los otros, regido por la interiorización de una pauta externa como es la del control del tiempo, el rigor intelectual y un modo de funcionamiento institucional organizado en base a reglas no negociables.

"Paula" es el seudónimo de una egresada, politóloga, entrevistada en París en 2004. Su familia vivía en Palermo y su padre era psicoanalista en el momento en que ocurrió ese encuentro. Ella relató su paso por el Colegio en términos de padecimiento. Como contracara de otros testimonios formulados en términos de premios y recompensas por el esfuerzo realizado, apareció en el relato de Paula la idea según la cual "el terror" sufrido puede no redundar en un éxito académico posterior:

Enseguida empezás a sentir todo lo que te hace sentir el Buenos Aires [...] la presión, la segregación, la elite [...] Vos empezás con un montón de gente, entre ellos tus amigos de la primaria, haciendo el curso de ingreso y vos entrás y los otros no. Cuando estás ahí adentro, vos tratás de construirte una vida a coté del Colegio pero no [...] [no se puede]. La verdad es que era complicado, era complicado mantener el contacto con el resto de la gente porque no entendías, vos tenías catorce años y el resto estaba boludeando y vos estabas encerrada estudiando todo el fin de semana. [...] Tenés quince años, hace dos años hiciste un curso de ingreso donde te dijeron: "Sos el mejor, pertenecés a la elite" y ahora te dicen: "Sos una basura, salí de acá, perdiste un año porque no te pudiste adaptar". Yo me comí una depresión los primeros dos años... infernal. Lo que te enseñan es eso, el rigor. Estar sentado todo el tiempo aterrorizado, todo el tiempo cagado en las patas. [...] Pero lo que te pasa, me parece, es que después de todo eso, todo ese terror a mí me dio paradójicamente una seguridad, es que yo nunca pensé que el estudio podía no ser para mí, nunca pensé que me podía ir mal en la facultad. Eso le pasó a mucha gente, se metieron en Ingeniería y los hicieron pomada.

Por lo demás, esa socialización resulta enriquecida por el intercambio de experiencias intelectuales, profesionales o políticas de las que participan como hijos, nietos o amigos, aunque se procesen colectivamente de un modo singular, por el que se reconocen entre sí egresados de todos los momentos del Colegio. Un entrevistado que fue docente del Colegio y ministro de economía lo explicaba del siguiente modo:

Por el ambiente, por las cosas que se discuten, por el calibre de lo que estudiás, por las personas que han pasado por acá, te inocula el virus de la cosa pública, aunque no te des cuenta, por las cosas que estás discutiendo, porque estás en contacto con realidades distintas, si bien en el ámbito intelectual estás en una suerte de microclima. Hay un componente muy importante de padres que han 
militado, y les legan eso a los hijos; los compañeros tienen conocimiento de procesos o de eventos políticos de primera mano porque han participado de cosas que vos leés en el libro de historia como anacrónicas.

A largo plazo el recuerdo de un tiempo compartido vivido como excepcional puede dar lugar a modos de relación que se sostienen en el tiempo en virtud de la conformación de redes profesionales a una escala relativamente amplia, formadas en base a la "confianza" que despierta en otros egresados ese "origen" común que funciona como una segunda naturaleza y puede llegar a activar el reconocimiento profesional.

La compañera de un egresado relató cómo su marido, un periodista que actualmente tiene cincuenta años, cuando conoce a alguien que le parece talentoso, lo busca en el libro del Colegio para determinar que sea realmente bueno. Con el tiempo la mujer se enteró de que el criterio utilizado por él para elegir al pediatra de sus hijos -al igual que para seleccionar a los padrinos- había sido que fueran todos egresados del CNBA. Una economista recibida en Chicago se encontró con un colega argentino, algunos años mayor, que había hecho el mismo recorrido académico que ella. "Él era una persona importante. Yo hablé un par de veces y el trato fue bueno, pero cuando surgió que yo, al igual que él, había ido al Buenos Aires...", hizo un gesto estirando el cuello, como dando a entender, corporalmente, que ella crecía ante los ojos de su interlocutor. Algo parecido le pasó al periodista ya mencionado con un altísimo funcionario del Ministerio de Justicia. El trato que le prodigaba era esquivo y estaba perjudicando su trabajo, hasta que él, advertido de su "origen" común, un día le dijo: "Yo soy egresado del Buenos Aires". "Me lo hubieras dicho antes", le contestó. Y la relación se modificó obviamente a su favor. Otro periodista, egresado de la Facultad de Ciencias Sociales, entró en el diario Página/12 gracias a una pasantía. Varios de los directores de ese medio son egresados del CNBA. "Empecé a darme cuenta de que había mucha gente, entre otros, los pasantes que habían entrado, que eran todos del Buenos Aires".

Esa pertenencia está trabajada también por prácticas como la del control de las respectivas trayectorias profesionales.

Retomando el planteo de las condiciones en las que se da nuestra lectura de La Nobleza... seria honesto decir que nosotras construimos primero el lugar, la "tradición", las discusiones, a partir del cual escribimos ambas investigaciones y recién después leímos el texto que hoy nos convoca. Ese desfasaje temporal posibilitó repensar nuestras interpretaciones con Bourdieu al mismo tiempo que establecíamos un diálogo entre nuestros trabajos. Esto nos deja una amplia gama de aperturas y nuevas preguntas que se van construyendo en esa relación.

\section{El problema del capital}

Bourdieu ha escrito que:

Si bien da la apariencia de una intensa mezcla aleatoria adecuada para abolir toda correspondencia entre la posición inicial y la posición final de los alum- 
nos tomados en cuenta, el sistema de enseñanza tiende a perpetuar el espacio de diferencias que lo separa antes de su intervención (Bourdieu, 2013:319).

En La Nobleza, el autor construye una sofisticada clasificación de estrategias de reproducción social de los sujetos según el tipo de capital de origen de que disponen -económico, social, simbólico- y a partir de allí construye dos tipos ideales de modos de reproducción social: el modo de reproducción familiar y el modo de reproducción con componente escolar. El primero consiste en una gestión puramente familiar de los problemas de reproducción y el segundo, en una gestión familiar que introduce cierto uso de la escuela en las estrategias de reproducción (Bourdieu, 2013:406).

Aquí, más que tomar posición sobre los términos del debate que estas ideas propician, nos interesa desplazar la atención de las conclusiones a los procesos, de las categorías explicativas resultantes de una elaboración a las condiciones de producción de esos modos de explicar. Pongamos como objeto la idea de "posición". Nos interesa tomar esas categorías bourdieusianas como categorías nativas, ya que como sostiene Florence Weber, todo discurso analizado es un discurso nativo. Empezamos de ese modo adoptando esa perspectiva (la de identificar una clasificación nativa) que es en definitiva una posición en el análisis. Cuando Bourdieu se refiere a "la posición inicial", parecería estar pensando en un espacio homogéneo, invariable, desprovisto de conflictos. ¿Qué lugar le otorga el autor a la socialización familiar? En nuestro trabajo de campo han aparecido en las trayectorias de egresados de un colegio público con ingreso restricto, signos que aluden a diferencias que hacen a la constitución de la posición inicial de los actores, por ejemplo, precisamente al interior de la socialización en las familias. Esa reflexión, como señalaron Stephen Beaud y Bernard Lahire, está ausente en nuestro autor. Algo similar ha escrito Florence Weber (Noiriel, 1990): "la teoría de Bourdieu es prácticamente muda sobre la socialización familiar".

Por caso, respecto del objetivo de formar escolarmente a las elites en Argentina, este aparece como un país en el que lo público no goza de la impronta que posee en Francia, desde 1789. Aquí, la ausencia de un esfuerzo inaudito para llevar a buen término los estudios secundarios no parece constituir una capitis diminutio ni una amenaza para el futuro de quien siguió otra vía menos sacrificada. Por lo anterior, no parece tan sencillo convencer a un joven de trece años de que haga el esfuerzo de transitar el proceso de ingreso al CNBA. O se lo puede convencer a él, pero a su hermano no. O puede ser que se lo convenza, pero no apruebe el examen. Por lo mismo, es posible que ese convencimiento le deba mucho a condiciones eminentemente individuales, $\mathrm{o}$, en otros términos, a trayectorias individuales dentro de las mismas familias. Quizás, por esa incertidumbre respecto del ingreso (entre otras razones), como han manifestado algunos egresados que además pertenecen a las familias tradicionales, no es factible depositar en la posibilidad incierta de convertirse en alumno del CNBA el trabajo de ligar generaciones al interior de una familia de clase alta. Lo que sucede, la mayoría de las veces, es que todos los hijos de una de estas familias son aceptados en colegios privados.

¿En qué medida la escuela elegida puede cambiar la posición final de dos personas que pertenecen a la misma familia? O en términos de Bourdieu, ¿cuánta posibilidad de triunfar tiene el achievement sobre la adscripción, lo que se ha conquistado sobre lo que se ha recibido? (Bourdieu, 2013: 19). 


\section{El hombre plural}

Quizá la respuesta a esa pregunta, como decíamos antes, esté atravesada por la impugnación que hace Lahire a la socialización primaria y secundaria. A partir de los resortes plurales de la acción documentados en El hombre plural es imposible no mirar con recelo construcciones como el "modo de reproducción familiar" y el "modo de reproducción con componente escolar". Bourdieu señala que estos modos de reproducción se diferencian entre sí debido a los usos que hacen de la escuela. Mientras que:

Para unos, el título escolar entregado por las instancias más escolares constituye la condición sine qua non del ingreso al campo de poder; los otros optan por instituciones escolares simultáneamente menos escolares y menos selectivas, las cuales (...) les conceden el mínimo de consagración necesario para ratificar situaciones adquiridas (Bourdieu, 2013:410).

Nuestros trabajos de campo muestran una heterogeneidad de sentidos y usos de la educación y de la escolarización dentro de las estrategias de reproducción social por las que no es posible establecer una jerarquización unívoca entre familia y escuela. La preeminencia de una u otra institución depende más bien de la posición social de cada uno de los sujetos y de sus trayectorias en una trama de relaciones. Los usos de la escuela y de las relaciones de parentesco como estrategias de reproducción asumen una combinación singular de registros diversos según los sujetos sociales concretos que hacen difícil pensar la existencia de dos modos de reproducción separados que no se reduzca a la construcción de un modelo típico ideal.

En el caso analizado por Gessaghi, los entrevistados otorgan una diversidad de sentidos a la escolarización en donde criterios "meritocráticos" asociados "a una educación de excelencia” se combinan con la adscripción a una "familia tradicional”. Más aún, la subsidiariedad de los títulos escolares respecto del "entramado familiar", en algunas trayectorias registradas, arroja luz sobre la importancia de disponer de soportes y sostenes para construir y disputar una posición de privilegio (Luci y Gessaghi, 2016). Así, un entrevistado de treinta y un años comentaba que no consideraba la necesidad de realizar estudios de posgrado universitario porque

Yo tengo suerte de que tengo mucho contacto así por onda familiar entonces creo que para una persona que por ahí nace sin contactos, un posgrado o estudiar afuera, le sirve muchísimo y más porque se hace amigos que son los que dirigen la batuta en sus respectivos países, eso es un entramado importante, pero eso en mi caso yo justo lo tenía. Mi hijo no sé si lo va a tener porque yo no me inserté tanto en el mundo así de los contactos. Bueno, [reflexiona] esperemos unos años, si todos los que yo conozco son el día de mañana poderosos.

Los sentidos que los sujetos que pertenecen a las "familias tradicionales" -en sus distintas posiciones sociales- otorgan a la educación, permiten poner en evidencia la ventaja de clase (Ball, 2001) que adquieren para ellos los criterios de adscripción por sobre la "meri- 
tocracia" en la reproducción de la vida cotidiana. En la experiencia analizada por Méndez ocurre algo similar, aunque la diversidad del origen familiar de los alumnos presenta casos individuales en los que la subsidiaridad de los títulos respecto del entramado familiar puede llegar a ser mínima, lo que permite pensar en trayectorias meritocráticas construidas a partir de saberes netamente escolares, redes informales de egresados, conformación de expectativas y acceso directo a modelos de ascenso social exitosos. En ese sentido, en dos hermanos que no poseen recursos significativos adquiridos por adscripción, el paso por el CNBA puede llegar a modificar sustancialmente el curso de las trayectorias y las posiciones profesionales ulteriores.

\section{La escuela consagra}

En instituciones que combinan un sistema estricto de ingreso con una base de reclutamiento heterogénea en la que existe cierto margen de posibilidad de que accedan individuos de zonas desfavorecidas, hay recursos que los alumnos adquieren en la misma socialización con otros alumnos que vienen de familias que gozan de privilegios de algún tipo. Son recursos que la escuela no provee en su curriculum pero que valora y consagra. En eso consiste su modelo de inculcación: en reservar sus favores a los que le deben menos en lo tocante a lo esencial (Bourdieu, 2013: 43). Los mismos alumnos son sancionadores y críticos respecto de las formas de hablar, los modales, las lecturas y los modos de esparcimiento de sus compañeros, con lo que definen un horizonte nuevo de lo "aceptable" en el medio escolar y quizás en futuros ámbitos de interacción. Así, algunos egresados de distintas edades fueron increpados o confesaron haber reprendido o ridiculizado a compañeros de colegio por decir "pieza" en lugar de "cuarto", o "cena" en lugar de "comida", por no ser idóneos u originales en su desempeño intelectual; por reírse a carcajadas, por vestir informalmente en un restaurant; por no saber lo que es un country. La publicación de una nota sobre el libro El Colegio (Méndez, 2013) fue una ocasión propicia para registrar acusaciones de toda índole entre egresados del CNBA y también proferidas por personas que fueron a otros secundarios. El más castigado fue un humorista gráfico que participó de la producción de fotos, a quién se lo acusó, entre otras cosas, de plagiario. Un egresado, a propósito de los modos y usanzas propios y de sus condiscípulos en los años del primer gobierno justicialista, señaló: "es 'cache' (poco elegante) competir con quien que sabe menos", e igualó esa falta de elegancia a la de reírse a carcajadas: "Eso era del pueblo, de personas de baja condición (...). Un 'señor' no se ríe a carcajadas”. En un twitt, una egresada del Buenos Aires de alrededor de cincuenta años mostraba no sin sarcasmo y gracia lo demudada que se encontraba por la actitud de un ex CNBA: el hombre acababa de llegar al prestigioso lugar en el que ambos trabajaban vestido con un sweater peruano (algo, para sus parámetros, claramente anacrónico y poco sofisticado).

También forjan nuevas expectativas cuyo cumplimiento es objeto de control por parte de los pares a lo largo de la vida. Bourdieu ha señalado que el capital cultural tiene como propiedad específica la de existir bajo la forma de esquemas de percepción y de acción, principios de visión y de división, de estructuras mentales (Bourdieu, 2013:19). ¿No es entonces posible afirmar que en una institución como el CNBA se construye capital cul- 
tural al interior de la misma relación social en la que se lo define como tal, si entendemos con Bourdieu que este no es otra cosa que una "relación social de poder en y debido al campo que constituye a las relaciones como objeto e instrumento de lucha" (Bourdieu, 2013: 368).

En el CNBA los alumnos conocen (porque se los han enseñado en el ingreso), el nombre de los egresados célebres, han leído alguna de sus autobiografías, comparten de primera mano experiencias familiares de sus pares como si fueran propias, se va definiendo un tipo de jerarquía que no necesariamente se sobreimprime siempre sobre un estamento social (la clase) pero crea lazos basados en la confianza que habilita la pertenencia a "un grupo al que se ofrece genéricamente la posibilidad del más encumbrado éxito (simbolizado por todos los alumnos célebres); autoriza una participación subjetiva y objetiva en ese éxito o mejor, en el capital simbólico asegurado al conjunto del grupo por el conjunto de las propiedades raras acumuladas por el conjunto de sus miembros, en especial, los más prestigiosos" (Bourdieu, 2013:165). En los colegios de la clase alta, también, aunque la jerarquía que se construye sí se sobreimprime sobre la clase.

Quizás esta idea de participación subjetiva en un colectivo que solo genéricamente ofrece la posibilidad de éxito explique el modo en que ciertos egresados que no han obtenido un éxito acorde al de los alumnos más célebres se comportan respecto del todo: acentuando la diferencia con quienes no pertenecen, trabajando por la continuidad del grupo al pretender controlar lo que sobre él se dice, organizando reuniones de ex alumnos en las que se reconfirman o reconstruyen lazos, se controla la trayectoria de los pares, como si estos otros fueran una medida de sí mismo. Algunos egresados se refirieron a lo que ocurre en las reuniones de egresados: el conteo de "conicets" (de los que entraron como investigadores a ese prestigioso organismo); "tirarse el vitae", es decir, hacer alarde de los logros académicos, en dichas reuniones; el muy habitual balance de compañeros que hicieron una carrera "buena y rápida", tantas veces relevado en las entrevistas. Un miembro de la Academia Nacional de Medicina se refirió en una de ellas a que entre sus compañeros "solo dos no eran profesionales".

Bourdieu ha escrito sobre "el amor a sí mismo en los otros, favorecido por la prolongada agrupación de semejantes" y ha encontrado allí "el auténtico fundamento del espíritu de cuerpo" (Bourdieu, 2013:256). Los no exitosos -decimos nosotras- participan de todos modos de lo que Bourdieu ha llamado "la suma siempre potencialmente movilizable de los capitales de todo tipo poseídos por cada uno de los miembros del grupo" (Bourdieu, 2013: 390).

A lo largo del trabajo de campo con escuelas de clase alta, algunos entrevistados señalaron la necesidad de pagar una membresía de adherencia inicial al inscribir a sus hijos en estas instituciones: entrar a esa escuela es como entrar a un club y participar de la vida de sus socios, de su estilo de vida, formar una comunidad, construir lazos en común por ser miembros. El colegio los provee de una "nueva identidad social": los costosos esfuerzos (monetarios, de movilización de la red social para conseguir referencias, de dedicación de tiempo para ir a sucesivas entrevistas) para ingresar se parecen a un rito de pasaje luego del cual, una vez adentro, los niños y sus familias son imbuidos de un "nuevo espíritu" o de un "spirit", como lo denominan algunos entrevistados. De esta manera, la escuela instaura una separación entre quienes son admitidos y quienes no. Realiza así su más importante 
trabajo: distingue y consagra (Bourdieu, 2013). Impone la creencia de que la clase alta es tal porque elige, y es elegida por, estas escuelas y no otras.

La escuela ejerce el poder de nominación de "las grandes familias": no a través del otorgamiento de credenciales educativas -como en el caso francés analizado por Bourdieu en La Nobleza de Estado- sino a través de la inclusión de los sujetos en una red de relaciones que construye al grupo social. Muchos se embarcan afanosamente en esa búsqueda. Otros entrevistados parecen no necesitarlo. Algunos, por momentos negocian con esa identidad $y$, en otros, la resisten.

La clase alta construye sentidos y prácticas en torno a las escuelas basados en la (re) creación cotidiana de las relaciones de conocimiento al interior de cada familia, entre ellas y entre las diversas generaciones que las componen. Potenciando una "íntima familiaridad", la escuela no "reproduce" la clase sino que participa de su producción. Las instituciones educativas no son un mero agente de la clase, son parte activa de ella (Connell, et al, 2000). Generan prácticas que promueven -no sin tensiones ni fracasos- la renovación, la integración, la reconstitución, la transformación y la prolongación de la clase alta a través del tiempo. Favorecen los intercambios legítimos y reúnen de forma aparentemente fortuita a individuos tan homogéneos como sea posible para la existencia y la persistencia del grupo (Bourdieu, 2013).

El caso de las familias tradicionales muestra que la reproducción asegurada por la herencia y el sostén de las relaciones significativas que sus miembros pueden movilizar para conservar o mejorar las condiciones de vida privilegiadas, vuelve innecesaria una apuesta fuerte por la educación formal. Pero no sólo eso. En un sistema educativo que otorga formalmente las mismas credenciales educativas a todos, se hace necesario producir una separación entre distinción social y acceso a dichas credenciales. La distinción implica entonces poder acumular recursos que no pueden ser adquiridos por todos en el mundo de la escuela.

Uno de los modos en que las sociedades modernas intentan consagrar una nobleza en el seno de una sociedad abierta y democrática tiene que ver con la atribución de una "dignidad" que otorgan los títulos extendidos por determinadas instituciones educativas. Esa "dignidad" está asociada a esquemas de clasificación tempranamente inculcados, que son de orden moral. En tanto una especie de capital (el capital cultural) lo moral ha de construirse al interior de una relación social y en referencia a la disputa por el poder al interior de un campo determinado. En las escuelas de la clase alta, eso considerado como moralmente distintivo y consagrado es "ser buenas personas"; los individuos pertenecen a "familias de buenas personas". Una entrevistada comparaba su colegio católico de mujeres con otro colegio privado laico bilingüe de zona norte, elegido por familias con un alto poder adquisitivo:

Para ellos todo era el éxito, ganar, ser el mejor. En [mi colegio] había que ser el mejor pero también ser buena persona. Ellos tenían algunas clases de ética pero en el fondo todo era ir hacia ser el numero uno (...) [Allí] hay más chicas que estudian una carrera universitaria o que siguieron trabajando en eso y en [mi colegio] por ahí menos (...) elegimos más la familia”. 
En el CNBA, lo moralmente distintivo tiene que ver el esfuerzo pero esa condición es encarnada por individuos que sortearon una instancia decisiva como la del ingreso, es decir que el Colegio los seleccionó al margen de la calificación moral de su familia, lo que no excluye distintos tipos de ayuda familiares ni el hecho de que el grupo parentesco pueda ver aumentada su "dignidad" una vez que uno de sus integrantes entró al Buenos Aires. Los sentidos diversos que se construyen sobre la meritocracia (en tanto acceso al saber o a ser "buenas personas") están dando cuenta de luchas al interior de las posiciones dominantes por imponer los criterios legítimos de legitimación (Bourdieu, 2013). La lectura de La Nobleza y nuestros intercambios nos permitieron desnaturalizar el trabajo de representación que realizan los sujetos por imponer su visión de la propia posición en el mundo (Bourdieu, 1985) y elegir ese debate como objeto de análisis más que tomar partido en él.

\section{Notas}

1. El trabajo de investigación se basó en 63 entrevistas abiertas en profundidad a adultos entre 80 y 30 años miembros de "familias tradicionales" con el objeto de reconstruir sus experiencias formativas. Si bien el campo elegido no se circunscribe a un territorio, se siguió la red de relaciones construida por los sujetos y las entrevistas se realizaron con personas que nos iban recomendando unas a otras. Se indagó respecto de tres generaciones dentro de cada familia intentando por este medio comprender las continuidades y transformaciones en sus trayectorias de vida. Como complemento de estas fuentes orales se utilizaron fuentes bibliográficas y material periodístico. Además se entrevistaron a otros informantes clave referidos por los entrevistados: ej. genealogistas; directores de guías sociales, entre otros. El trabajo de campo incluyó, igualmente, el análisis de biografías escritas por miembros de las "grandes familias", libros editados por ellos, que fueron entregados a la investigadora durante las entrevistas. El trabajo con fuentes se completó con libros consultados en la biblioteca del Jockey Club de Buenos Aires sobre "la clase alta" y el registro hemerográfico centrado en las referencias a las "grandes familias" en los principales diarios de tirada nacional (Clarín, La Nación y Página 12) entre los años 2006 y 2010. Finalmente, se realizaron observaciones -a veces participantes- en eventos "de caridad" realizados por las escuelas a las que asisten los entrevistados y de diversas situaciones institucionales (actos escolares, entradas y salidas de las escuelas, entre otras).

2. Revista de Asociación de ex alumnas (AEA) de una de las escuelas estudiadas en Gessaghi, 2016.

\section{Bibliografía}

Ball, S. (2001). Class Strategies and the Education Market.Londres, ReinoUnido: Routledge. Beaud, S. (2002). 80\% au bac...etapres? Les enfants de la démocratization scolaire. Paris, Francia: La Découverte/Poche.

Bourdieu, P. (1985). Respuestas por una antropología reflexiva. México DF, México: Grijalbo. 
(2013). La nobleza de Estado. Educación de élite y espíritu de cuerpo.Buenos Aires, Argentina: Siglo XXI.

Connell, R. (2000). Class and gender dynamics in a ruling-class school. En B. Levinson y K. M. Borman (Ed.).Schooling the Symbolic Animal. Social and Cultural Dimensions of Education (296-313).Lanham, Maryland, EstadosUnidos: Rowman \& Littlefield.

Gessaghi, V. (2016). La educación de la clase alta Argentina. Entre la herencia y el mérito. Buenos Aires, Argentina: Siglo XXI.

Luci, F. y Gessaghi, V. (2016). Familias tradicionales y elites empresarias en Argentina: individuación y solidaridad en la construcción y sostén de las posiciones de privilegio. En Política, Revista de Ciencia Política de la Universidad de Chile, 54 (2).

Lahire, B. (2008). Socializaciones y disposiciones heterogéneas: sus vínculos con la escolarización". Propuesta Educativa, 17(30).

Levi, G.(1989). Les usages de la biographie. Annales. Économies, Sociétés, Civilisations. 44(6). Méndez, A. (2013). El Colegio. La formación de una élite meritocrática en el Nacional de Buenos Aires, Argentina: Sudamericana.

Noiriel, G. (1990). Journal de terrain, journal de recherche et auto-analyse. Entretienavec Florence Weberen: Genèses.Année1990, 2(2).

\begin{abstract}
The paper analyzes the reading conditions of Bourdieu's book: The State Nobility in relation to two investigations that address the education of two privilege groups in Argentine society. We are interested in placing different accents to the text in question, by virtue of how some problems of the nobility resonate in the field work carried out in these investigations. Firstly, the article explores the reception that Bourdieu's seminal work had in our field and highlights its main contributions for the study of elites in Argentina. Next, it describes the ways in which the "effect of dignity" granted by a title as conceptualized by Bourdieu in his work unfolds in our respective fields. Finally, the various ways in which, in the cases studied, capital is constructed, combined, reproduced; and the place elite schools occupies in that construction.
\end{abstract}

Keywords: State nobility - Bourdieu - High class - Nacional Buenos Aires Colledge - meritocracy.

Resumo: O trabalho analisa as condições de leitura do libro A Nobreza do Estado no marco de duas investigações que abordam a educação de dois grupos de privilégios na sociedade argentina. As autoras estão interessadas em colocar diferentes sotaques no texto em questão, em virtude de como alguns problemas da nobreza ressoam no trabalho de campo levado adiante nessas investigações. $\mathrm{O}$ artigo explora em primeiro lugar a recepção que a obra seminal de Bourdieu teve em nosso campo e destaca suas principais contribuições para o estudo das elites na Argentina.seguida, descreve as maneiras pelas quais o "efeito da dignidade" (Bourdieu, 2013) concedido por um título, se desdobra em nossos respec- 
tivos campos. Finalmente, as varias maneiras pelas quais, nos casos estudados, o capital é construído, combinado, reproduzido; e o lugar ocupa as escolas de elite nessa construção.

Palavras chave: Nobreza do Estado - Bourdieu - classe alta - Colegio Nacional do Buenos Aires - meritocracia.

[Las traducciones de los abstracts fueron supervisadas por el autor de cada artículo] 